\title{
Purity of Ion Beams: Analysis and Simulation of Mass Spectra and Mass Interferences in Ion Implantation
}

\author{
Volker Häublein, ${ }^{1}$ Heiner Ryssel, ${ }^{1,2}$ and Lothar Frey ${ }^{1,2}$ \\ ${ }^{1}$ Fraunhofer Institut für Integrierte Systeme und Bauelementetechnologie, Schottkystrasse 10, 91058 Erlangen, Germany \\ ${ }^{2}$ Lehrstuhl für Elektronische Bauelemente, Universität Erlangen, Cauerstrasse 6, 91058 Erlangen, Germany
}

Correspondence should be addressed to Volker Häublein, volker.haeublein@iisb.fraunhofer.de

Received 1 July 2011; Accepted 5 August 2011

Academic Editor: Joseph Gyulai

Copyright ( $) 2012$ Volker Häublein et al. This is an open access article distributed under the Creative Commons Attribution License, which permits unrestricted use, distribution, and reproduction in any medium, provided the original work is properly cited.

\begin{abstract}
This paper shows that charge exchange events and dissociation reactions of ions may impact the purity of the ion beam in ion implantation, leading to contamination of the implanted target. Physical relations are derived that explain why unwanted ions are transported in the ion beam despite of a magnetic mass separation. Based on those relations, the simulation tool ENCOTION (ENergetic COntamination simulaTION) has been developed. ENCOTION is a very powerful tool for the simulation of transport mechanisms of ions through a magnet analyzer and for the simulation of mass spectra, as will be demonstrated in this paper.
\end{abstract}

\section{Introduction}

The modification of materials by ion implantation offers major advantages, such as high dose accuracy, excellent reproducibility, or low process temperatures. Due to its mass separation, ion implantation is considered to be an extremely clean process step. Many applications, such as CCDs or bipolar devices, strongly depend on the purity of the ion beam [1]. The coimplantation of other contaminating ion species might lead to serious consequences:

(i) dose errors, especially when the amount of contaminating ions is significantly high;

(ii) differences in the defect formation, for example, when the contaminating ion species is much heavier than the desired ion species;

(iii) impairment or complete malfunction of the irradiated device, for example, in bipolar devices when the contaminating ion species forms deep recombination centers;

(iv) unreproducible implantation results as the composition of the ion beam might change with source parameters (especially temperature) as well as with the history of the ion source.
Basically, mass interferences occur when the masses of different ion species are so close that the analyzer magnet cannot separate them. For example, As may be implanted together with Ge, when As is directly implanted after a Ge preamorphization implant [2]. A key parameter for mass separation, therefore, is the mass resolution $M / \Delta M$ which can have great impact on the ion beam composition [3]. The higher the mass resolution is, the lower the risk for contamination is. Modern ion implanters have mass resolutions in the range of about 15 to 90, whereas for the purpose of a high ion beam purity, a value of more than 100 is recommended [3].

Since mass separation is accomplished by magnetic fields, it is well known that the ions are not separated by their mass, but rather by the mass to charge state ratio. A prominent example for contamination from device manufacturing is the coimplantation of doubly charged Mo during $\mathrm{BF}_{2}$ implantation where the mass to charge state ratio is 49 in both cases $[4,5]$. The simultaneous implantation of unwanted ions with the same mass to charge ratio as the desired ion species might appear to be a manageable contamination risk, but it is only a special case. When ions undergo a charge exchange or dissociate between the ion source and the analyzer magnet, surprising contamination issues may arise [68 ]. This paper illustrates by means of mass spectrum analysis 
(which is not only essential in order to check which elements are present in the ion source) that charge exchange events and dissociation processes between the ion source and the analyzer magnet of an implanter are fairly common. In this regard, an important result of this paper is that those reactions generally produce two peaks in a mass spectrum, whereof one not only depends on the mass and charge states of the considered ions, but also on the extraction and suppression voltages of the implanter. Simulations with the presented tool ENCOTION reveal that those charge exchange and dissociation processes basically allow for a large variety of potential transport mechanisms for practically all elements.

\section{Apparent Mass Concept}

The derivation of the apparent mass models is based on the equation of Lorentz force and centrifugal force:

$$
B q_{\mathrm{an}} e v=\frac{m_{\mathrm{an}} v^{2}}{r}
$$

where $B$ is the magnetic flux density, $r$ the radius of the magnet, $e$ the elementary charge, $v$ the velocity of the analyzed ion, and $m_{\mathrm{an}}$ and $q_{\mathrm{an}}$ are mass and charge state of the ion in the analyzer.

Three sections have to be distinguished in the beamline from the ion source to the analyzer magnet (see Figure 1):

(1) $[$ Src-Ex] section between ion source and extraction electrode;

(2) $[$ Ex-Gnd] section between extraction and ground electrode;

(3) [Gnd-An] section between ground electrode and analyzer.

When a mass or charge exchange event occurs within section [Src-Ex] or section [Ex-Gnd], the final velocity of an ion in the magnet depends on the exact position in those sections. Therefore, the variables $z_{\mathrm{ex}}$ and $z_{\mathrm{sp}}$ describe the relative position of the charge or mass changing event in section [Src$\mathrm{Ex}$ ] and section [Ex-Gnd], respectively, and take values from 0 to 1 (see Figure 1). Under the assumptions that in any of the three sections no more than one charge or mass changing event takes place and that the impact of the event itself on the velocity is negligible, the velocity of the ion in the magnet calculates as follows:

$$
v=\sqrt{2 e} \cdot \sqrt{\left(\frac{q_{\mathrm{sc}}}{m_{\mathrm{sc}}} z_{\mathrm{ex}}+\frac{q_{\mathrm{ex}}}{m_{\mathrm{ex}}}\left(1-z_{\mathrm{ex}}\right)\right)\left(V_{\mathrm{ex}}+V_{\mathrm{sp}}\right)-\left(\frac{q_{\mathrm{ex}}}{m_{\mathrm{ex}}} z_{\mathrm{sp}}+\frac{q_{\mathrm{sp}}}{m_{\mathrm{sp}}}\left(1-z_{\mathrm{sp}}\right)\right) V_{\mathrm{sp}}}
$$

where $m_{\mathrm{sc}}$ and $q_{\mathrm{sc}}$ are mass and charge state of an ion leaving the ion source, $m_{\mathrm{ex}}$ and $q_{\mathrm{ex}}$ are mass and charge state at the extraction electrode, and $m_{\mathrm{sp}}$ and $q_{\mathrm{sp}}$ are mass and charge state at the ground electrode. Inserting (2) in (1), a general expression for the apparent mass can be derived:

$$
\begin{aligned}
m_{\mathrm{app}}=\frac{m_{\mathrm{an}}^{2}}{q_{\mathrm{an}}^{2}}[ & \left(\frac{q_{\mathrm{sc}}}{m_{\mathrm{sc}}} z_{\mathrm{ex}}+\frac{q_{\mathrm{ex}}}{m_{\mathrm{ex}}}\left(1-z_{\mathrm{ex}}\right)\right)\left(1+\frac{V_{\mathrm{sp}}}{V_{\mathrm{ex}}}\right) \\
& \left.-\left(\frac{q_{\mathrm{ex}}}{m_{\mathrm{ex}}} z_{\mathrm{sp}}+\frac{q_{\mathrm{sp}}}{m_{\mathrm{sp}}}\left(1-z_{\mathrm{sp}}\right)\right) \frac{V_{\mathrm{sp}}}{V_{\mathrm{ex}}}\right] .
\end{aligned}
$$

According to (3), the apparent mass depends not only on the mass and charge states of the ions, but also on the ratio of suppression and extraction voltage. Because of the variables $z_{\mathrm{ex}}$ and $z_{\mathrm{sp}}$, the apparent mass is not limited to discrete values but can take values from a continuous range. Equation (3), therefore, is appropriate to describe tails of peaks in a mass spectrum, such as the Al tail in Figure 4 in the next section or to model contamination problems where the charge exchange occurs in section [Src-Ex] [8].

In order to describe and simulate peaks of a mass spectrum, (3) can be simplified by applying the following assumptions:

(i) on its way from the ion source to the analyzer magnet, an ion undergoes no more than one change in mass or charge state; (ii) the charge or mass change events occur either at the suppression or the ground electrode $\left(z_{\mathrm{ex}}=z_{\mathrm{sp}}=1\right)$ or between ground electrode and magnet.

According to those assumptions, two expressions for the apparent mass can be derived:

(1) charge exchange or dissociation at extraction electrode $\left(m_{\mathrm{an}}=m_{\mathrm{sp}}, m_{\mathrm{sc}}=m_{\mathrm{ex}}, q_{\mathrm{an}}=q_{\mathrm{sp}}\right.$, and $q_{\mathrm{sc}}=$ $\left.q_{\mathrm{ex}}\right)$ :

$$
m_{\mathrm{app}}=\frac{m_{\mathrm{an}}^{2}}{q_{\mathrm{an}}^{2}}\left[\frac{q_{\mathrm{sc}}}{m_{\mathrm{sc}}}+\frac{V_{\mathrm{sp}}}{V_{\mathrm{ex}}} \cdot\left(\frac{q_{\mathrm{sc}}}{m_{\mathrm{sc}}}-\frac{q_{\mathrm{an}}}{m_{\mathrm{an}}}\right)\right],
$$

(2) charge exchange or dissociation at ground electrode or beyond $\left(m_{\mathrm{sc}}=m_{\mathrm{ex}}=m_{\mathrm{sp}}\right.$ and $\left.q_{\mathrm{sc}}=q_{\mathrm{ex}}=q_{\mathrm{sp}}\right)$ :

$$
m_{\mathrm{app}}=\frac{m_{\mathrm{an}}^{2}}{q_{\mathrm{an}}^{2}} \frac{q_{\mathrm{sc}}}{m_{\mathrm{sc}}} .
$$

Both expressions for the apparent mass, (4) and (5), yield discrete mass values. The particularity of (4) is the dependence of the apparent mass on the ratio of the extraction and suppression voltages, while the apparent mass according to (5) only depends on masses and charge states of the considered ions. Equation (5) is well known and has been widely used to explain contamination issues in ion implantation $[9,10]$. Both equations are the fundament for understanding a variety of peaks in mass spectra. 


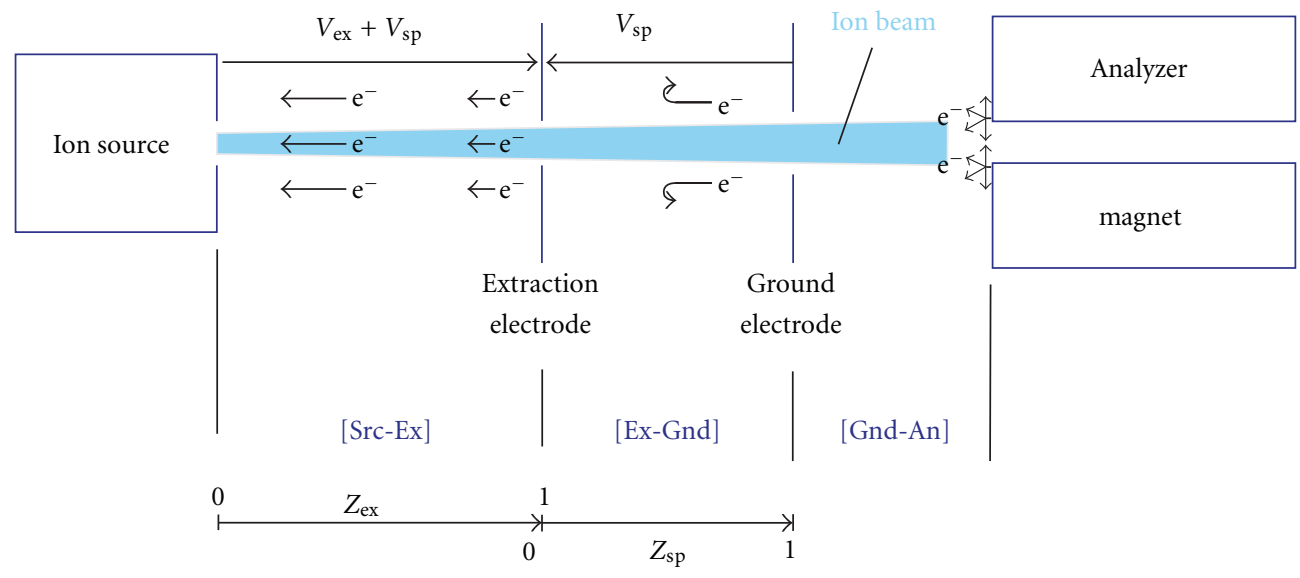

FIGURE 1: Layout of the beamline of an implanter from ion source to analyzer magnet. The beamline is divided into the three sections [SrcEx], [Ex-Gnd], and [Gnd-An]. The ion beam generates secondary electrons which are accelerated in the sections [Src-Ex] and [Ex-Gnd].

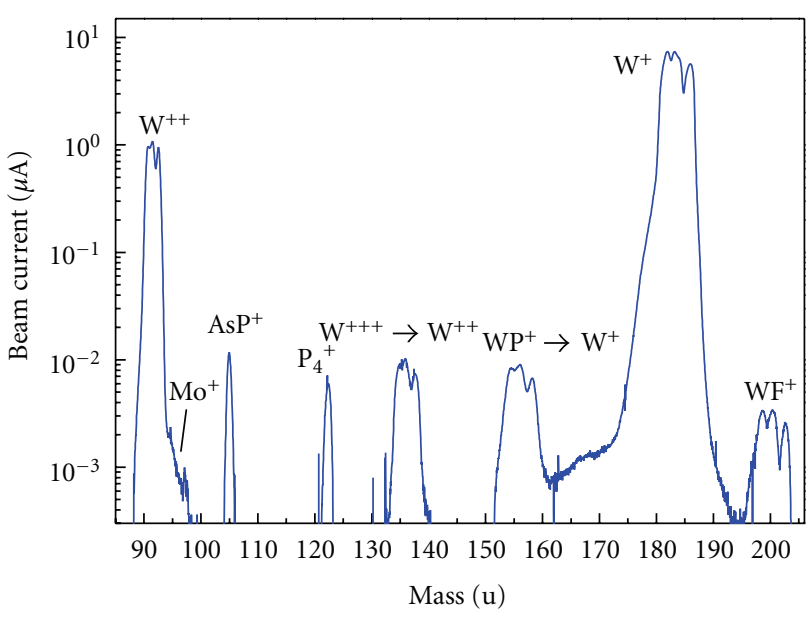

Source gas: $\mathrm{PH}_{3}$

Extraction voltage: $20.2 \mathrm{kV}$

Figure 2: Section of a $\mathrm{PH}_{3}$ mass spectrum.

\section{Analysis of Mass Spectra}

A set of mass spectra with different source feed materials, such as $\mathrm{AsH}_{3}, \mathrm{PH}_{3}, \mathrm{~N}_{2}, \mathrm{BF}_{3}$, and $\mathrm{Al}$ were recorded and analyzed. The mass spectra were recorded on a Varian $350 \mathrm{D}$ implanter with a mass resolution $M / \Delta M$ between 100 and 120 . The Freeman ion source consists of a molybdenum arc chamber and a tungsten filament which is insulated by alumina ceramics. The recording of the spectra and the control of the analyzer magnet were accomplished by a self-programmed LabView software. It is of great importance that the ion current can be recorded over several orders of magnitude. In the following, selected sections of the mass spectra are depicted in order to demonstrate the occurrence of charge exchange and dissociation reactions.

Figure 2 shows a mass spectrum from $85 \mathrm{u}$ to $220 \mathrm{u}$ for an ion source being operated with $\mathrm{PH}_{3}$. Tungsten with its five isotopes produces a very characteristic arrangement of $\mathrm{W}^{+}$

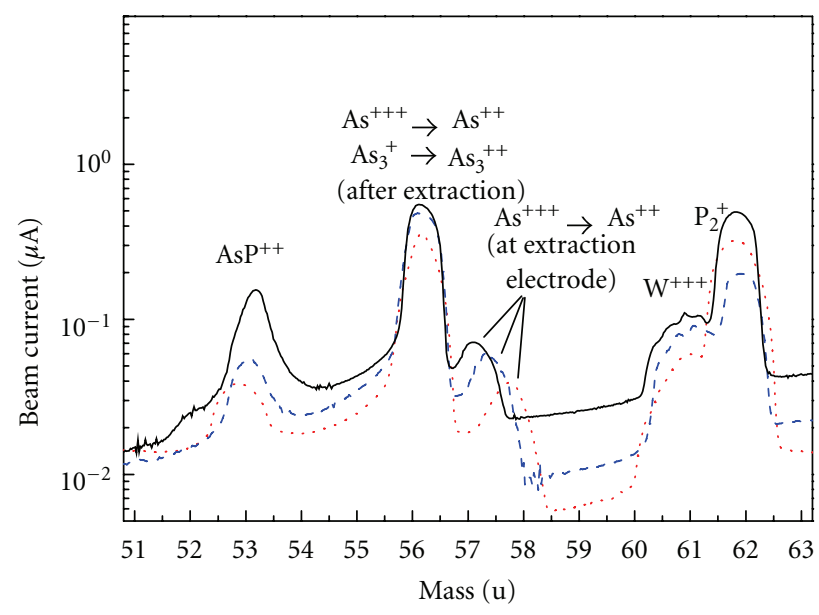

Source gas: $\mathrm{AsH}_{3}$

Extraction voltages:

$-30.1 \mathrm{kV}$

$---25.1 \mathrm{kV}$

… $20.2 \mathrm{kV}$

Figure 3: Section of an $\mathrm{AsH}_{3}$ mass spectrum.

peaks between $180 \mathrm{u}$ and $186 \mathrm{u}$. In Figure 2, this arrangement of peaks also shows up at four other positions. The peaks from $90 \mathrm{u}$ to $93 \mathrm{u}$ and from $199 \mathrm{u}$ to $205 \mathrm{u}$ represent the signals of $\mathrm{W}^{++}$and $\mathrm{WF}^{+}$ions, respectively. The remaining $\mathrm{W}$ peaks are caused by charge exchange and dissociation reactions. The peaks from $135 \mathrm{u}$ to $139 \mathrm{u}$ and $150 \mathrm{u}$ to $156 \mathrm{u}$, are the results of the charge exchange reaction $\mathrm{W}^{+++} \rightarrow \mathrm{W}^{++}$ and the dissociation process $\mathrm{WP}^{+} \rightarrow \mathrm{W}^{+}$, respectively.

Figure 3 shows three mass spectra from $51 \mathrm{u}$ to $63 \mathrm{u}$, each recorded at a different extraction voltage, and the source feed gas was $\mathrm{AsH}_{3}$. The signal at mass $56.2 \mathrm{u}$ is attributed to As and can be caused in agreement with (5) by two different charge exchange mechanisms:

(i) $\mathrm{As}^{+++} \rightarrow \mathrm{As}^{++}$(at or beyond ground electrode),

(ii) $\mathrm{As}_{3}{ }^{+} \rightarrow \mathrm{As}_{3}{ }^{++}$(at or beyond ground electrode). 


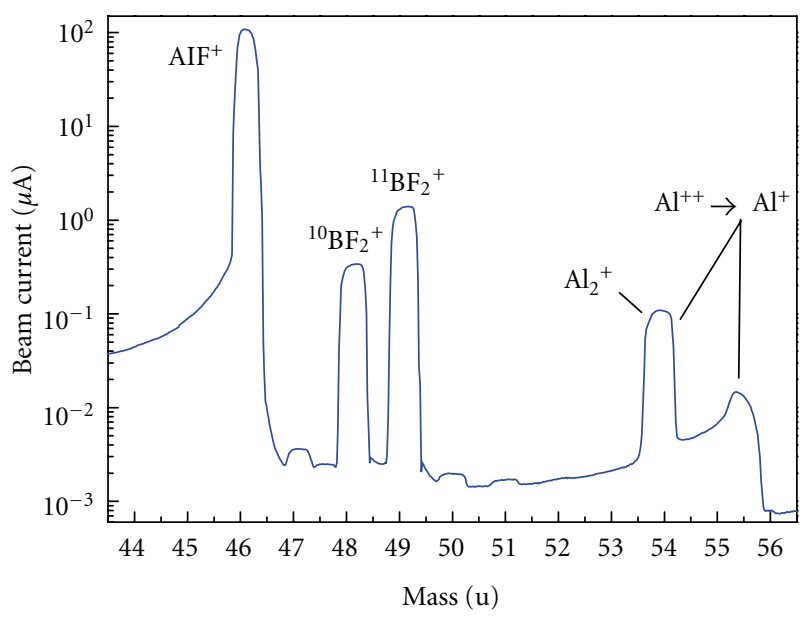

Source feed: Al

FIgURE 4: Section of an aluminum mass spectrum.

Noticeable is the peak between $57 \mathrm{u}$ and $58 \mathrm{u}$ which obviously changes its position with the extraction voltage. In Table 1, the measured masses are compared to the apparent masses of the two mechanisms according to (4) and (5). For the mechanism $\mathrm{As}^{+++} \rightarrow \mathrm{As}^{++}$, there is an excellent agreement, also the peaks between $57 \mathrm{u}$ and $58 \mathrm{u}$ are accurately described. As regards the mechanism $\mathrm{As}_{3}{ }^{+} \rightarrow \mathrm{As}_{3}{ }^{++}$(at or beyond ground electrode), no explicit peaks related to a charge exchange at the extraction electrode were detected in the range from $51.74 \mathrm{u}$ to $53.20 \mathrm{u}$, suggesting that the mechanism $\mathrm{As}^{+++} \rightarrow \mathrm{As}^{++}$is much more pronounced.

Figure 4 shows the section of a mass spectrum of Al. Besides $\mathrm{Al}, \mathrm{BF}_{2}$ ions can be found from previous operation with $\mathrm{BF}_{3}$ as well as a comparatively large peak of $\mathrm{AlF}^{+}$. The peak at $54 \mathrm{u}$ can be either built up by $\mathrm{Al}_{2}{ }^{+}$ions or by the charge exchange mechanism $\mathrm{Al}^{++} \rightarrow \mathrm{Al}^{+}$. The peak at $55.3 \mathrm{u}$ is caused when this mechanism takes place at the extraction electrode. It is striking that this signal shows a large tail towards lower masses down to approximately $50.5 \mathrm{u}$. The reason for this tail is that the charge exchange takes place not only directly at the extraction electrode but also between the ion source and the extraction electrode, with decreasing frequency towards the ion source.

In Figures 5 and 6, the sections of a $\mathrm{N}_{2}$ and a $\mathrm{BF}_{3}$ spectrum, respectively, are depicted. For lower masses, mass separation works quite effectively, and, therefore, a large variety of peaks can be seen. In Figure 5, for example, more than 20 peaks can be distinguished. With (4) and (5), practically all of the peaks can be explained using only the elements which are known to be present in the ion source. Both spectra show that the charge state of the ions is not always diminished as it was the case for $\mathrm{W}, \mathrm{As}$, and $\mathrm{Al}$ in the previous spectra. For N (Figure 5) and for B (Figure 6), the ionization reactions $\mathrm{N}^{+} \rightarrow \mathrm{N}^{++}$and $\mathrm{B}^{+} \rightarrow \mathrm{B}^{++}$, respectively, are observed.

The considered mass spectra show quite many peaks caused by charge exchange or dissociation processes. Especially the charge exchange reactions $\mathrm{A}^{+} \rightarrow \mathrm{A}^{++}, \mathrm{A}^{++} \rightarrow \mathrm{A}^{+}$,

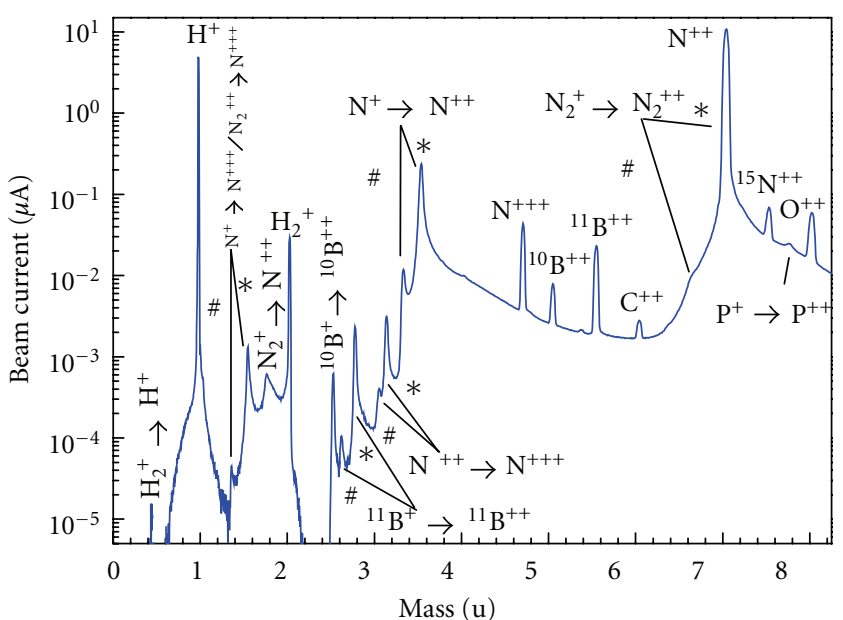

Source gas: $\mathrm{N}_{2}$

Charge/mass charge:

$*$ : After extraction

\# : At extraction electrode

Figure 5: Section of an $\mathrm{N}_{2}$ mass spectrum.

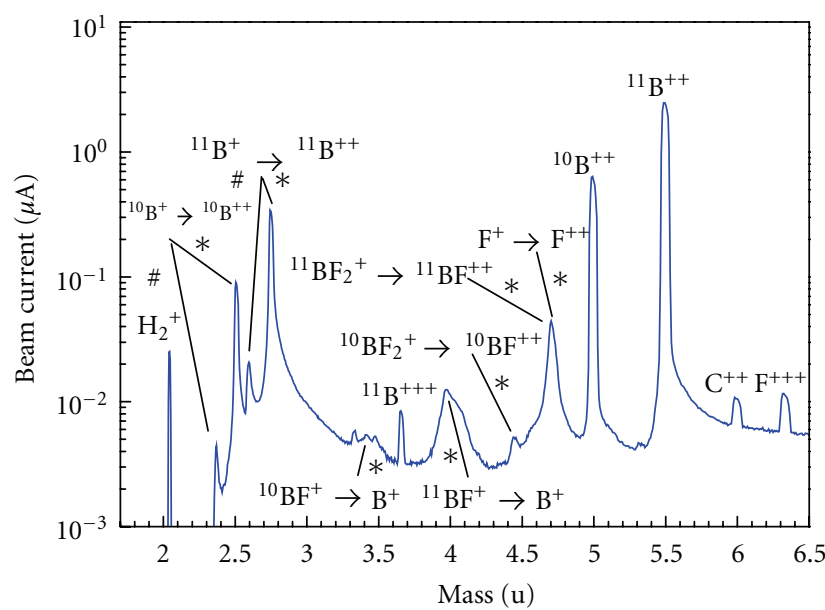

Source gas: $\mathrm{BF}_{3}$

$*$ : After extraction

\# : At extraction electrode

FIgURE 6: Section of a $\mathrm{BF}_{3}$ mass spectrum.

$\mathrm{A}^{++} \rightarrow \mathrm{A}^{+++}$, and $\mathrm{A}^{+++} \rightarrow \mathrm{A}^{++}$, with $\mathrm{A}$ representing any element of the periodic table, can be found regularly. Those mechanisms lead to two signals in the mass spectrum, one of them being dependent on the ratio of the extraction and suppression voltage. Those peaks might be accompanied by large tails, increasing the risk of contamination significantly.

\section{Simulation of Mass Spectra and Mass Interferences}

4.1. Software Tool ENCOTION. ENCOTION (ENergetic COntamination simulaTION) is a simulation tool which 
TABle 1: Comparison of As peaks from Figure 3 with calculated apparent masses. Spectrum (a) charge exchange after extraction, spectrum and (b) charge exchange at the extraction electrode $V_{\text {sp }}=1.6 \mathrm{kV}$.

\begin{tabular}{lccccc}
\hline Mechanism & $V_{\text {ex }}(\mathrm{kV})$ & & & $m_{\text {app }}(\mathrm{u})$ & \\
& & Spectrum (a) & Equation (5) & Spectrum (b) & Equation (4) \\
\hline \multirow{2}{*}{$\mathrm{As}^{+++} \rightarrow \mathrm{As}^{++}$} & 20.2 & 56.21 & 56.19 & 57.79 & 57.68 \\
& 25.1 & 56.20 & 56.19 & 57.41 & 57.39 \\
& 30.1 & 56.20 & 56.19 & 57.17 & 57.19 \\
\hline \multirow{2}{*}{$\mathrm{As}_{3}{ }^{+} \rightarrow \mathrm{As}_{3}{ }^{++}$} & 20.2 & 56.21 & 56.19 & n. d. & 51.74 \\
& 25.1 & 56.20 & 56.19 & n. d. & 52.61 \\
& 30.1 & 56.20 & 56.19 & n. d. & 53.20 \\
\hline
\end{tabular}

was originally developed in order to check the potential of any element of the periodic table to contaminate the target during the ion implantation process [11]. It enables the user to simulate expeditiously transport mechanisms of contaminants through the analyzer magnet, taking charge exchange reactions and dissociation of molecular ions into account. ENCOTION contains a database featuring the complete periodic table of elements. Names and symbols of the elements with atomic numbers greater than 100 were chosen according to the recommendations of the International Union of Pure and Applied Chemistry (IUPAC) [12]. The database contains the masses and abundances of all natural isotopes, and the values were taken from IUPAC tables [13].

Since the first version of ENCOTION was released [14], numerous improvements were made and extensions were added. ENCOTION now considers changes in mass and charge state at the extraction electrode according to (4). Figure 7 shows the parameter dialog where the main settings for a simulation are made. Essential for a simulation are the definition of the apparent mass (which is preferably done by specifying the implanted ion species in order to consider decimals of the apparent mass) and the definition of the contaminating element. Additionally, assisting elements can be specified which might form a molecule with the contaminating elements but which are not necessarily implanted. For simulating changes in mass or charge state at the extraction electrode, the extraction and suppression voltage have to be provided. The extraction and a postacceleration voltage are needed to calculate the effective energy of the coimplanted contaminating element. Other parameters, such as mass resolution, maximum charge state, or maximum number of contaminants in a molecule, may be used to limit or to extend the solution space. In Figure 8, a result window with simulated transport mechanisms is depicted. For each transport mechanism, the extracted ion with charge state as well as the analyzed ion with charge state are listed. In addition, the effective energies of the contaminating element with and without an acceleration after mass separation are provided. Finally, the apparent mass and the difference to the implanted mass are listed. All columns of the result window can be sorted in descending or ascending order.

A major extension is the implementation of two graphical modules for simulating mass spectra. The first module simulates the spectrum peaks of two interfering ion species either by Gaussian curves or by consideration of geometric parameters, such as the magnet radius, the width of the beam slit, and the standard deviation of the ion beam. The latter is especially useful when the width of the mass resolving slit is larger than the deviation of the ion beam. The peaks can be plotted both linearly and logarithmically. Figure 9 shows an example of a mass spectrum of Ge interfering with W.

The second module simulates mass spectra with up to five elements, taking into account multiply charged ions and the formation of molecular ions. In Figure 10, a window with simulated mass spectra from 0 to $200 \mathrm{u}$ is shown. The peaks are formed only by the elements B, O, F, Mo, and W under consideration of multiply charged ions and the formation of molecular ions. ENCOTION allows for the comparison of two spectra. The total of the (red and blue) peaks describes the spectrum spanned by all five elements. The red peaks were simulated with Mo being removed, that is, the remaining blue peaks are caused by ions containing Mo. The combination of the simulation of transport mechanisms together with the graphical simulation of mass spectra makes ENCOTION an optimum tool for identifying peaks in measured mass spectra.

4.2. Simulation of Mass Spectra. To identify unknown peaks in mass spectra, the simulation of transport mechanisms can be complemented by the simulation of graphical mass spectra. This is especially promising when elements with more than one isotope are involved. In Figure 11, a $\mathrm{BF}_{3}$ mass spectrum from $108 \mathrm{u}$ to $120 \mathrm{u}$ is shown. None of the peaks features tails or shoulders which might indicate that they are built by superpositions of different peaks. In fact, the simulation with ENCOTION reveals that the peaks are caused by a superposition of $41.7 \% \mathrm{MoO}^{+}$and $58.3 \% \mathrm{MoF}^{+}$ions. In case that the magnet analyzer would be set to mass $114 \mathrm{u}$, the ion beam would consist of $26 \%{ }^{98} \mathrm{Mo}, 24 \%{ }^{95} \mathrm{Mo}, 26 \%{ }^{16} \mathrm{O}$, and $24 \%{ }^{19} \mathrm{~F}$.

Another spectrum simulation is shown in Figure 12. The ion source was initially operated with $\mathrm{AsH}_{3}$ for As implantation, when subsequently the source feed gas was switched to $\mathrm{N}_{2}$. At mass $75 \mathrm{u}$, the $\mathrm{As}^{+}$peak is visible. In the mass region between $69 \mathrm{u}$ and $74 \mathrm{u}$, the measurement indicates a few more peaks. It is striking that the distance of the peaks between $70 \mathrm{u}$ and $72 \mathrm{u}$ is not $1 \mathrm{u}$ but $0.75 \mathrm{u}$. The mass spectrum simulation with ENCOTION identifies those peaks to be caused by the charge exchange reaction $\mathrm{Mo}^{+++} \rightarrow \mathrm{Mo}^{++}$. In 


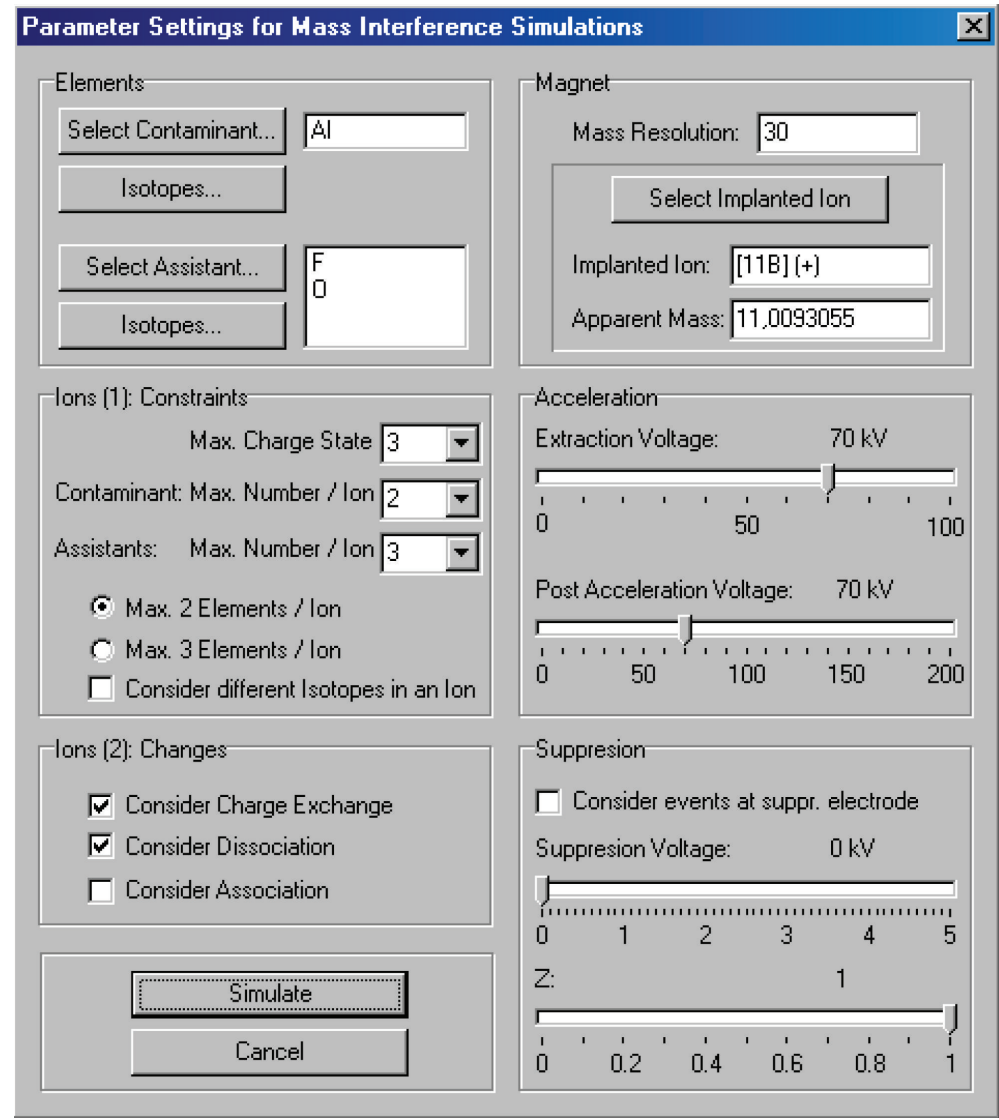

FigURE 7: Parameter dialog of ENCOTION. In this dialog, the main parameters, such as the implanted ion species and the contaminating elements, are specified.

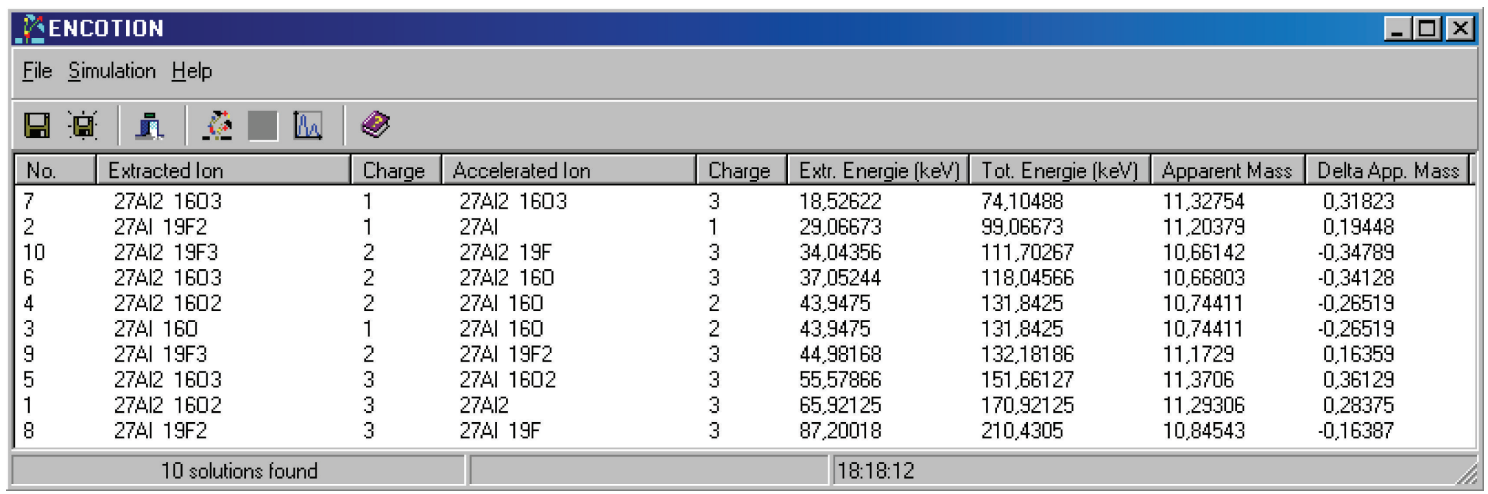

FIGURE 8: Result window of ENCOTION. The simulated transport mechanisms are organized in nine sortable columns, containing the extracted and analyzed ions, the effective energies of the contaminating element with and without postacceleration, the simulated apparent mass, and the mass difference to the apparent mass of the implanted ion. In this example, the simulated transport mechanisms of Al during ${ }^{11} \mathrm{~B}^{+}$implantation are listed, sorted by effective energy in ascending order.

this case, the peak caused by ${ }^{100}$ Mo overlaps exactly with the peak of As, that is, the As beam is contaminated with ${ }^{100} \mathrm{Mo}$.

\subsection{Identification of Contamination Mechanisms. In many} cases, simulations with ENCOTION show surprisingly large numbers of possibilities of how a peak in a mass spectrum might be caused or how an unwanted element might con- tribute to contamination of the implanted target. This makes it sometimes difficult to unambiguously assign the cause of a peak in a mass spectrum, especially when only elements with one isotope come into consideration. For ion implantation, the peak of the desired ion species is aimed to be tuned as large as possible, making it in most cases impossible to rate whether this peak conceals peaks of other ion species or 


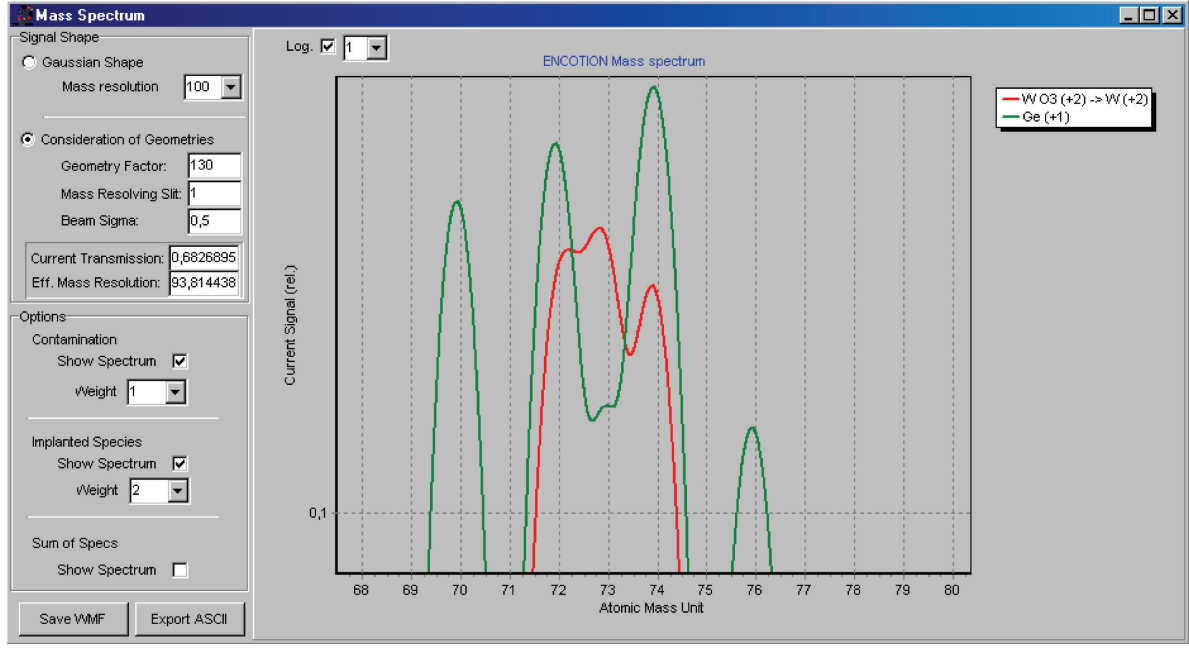

Figure 9: Mass spectrum module 1 of ENCOTION. The simulated spectra show an interference between Ge and W ions.

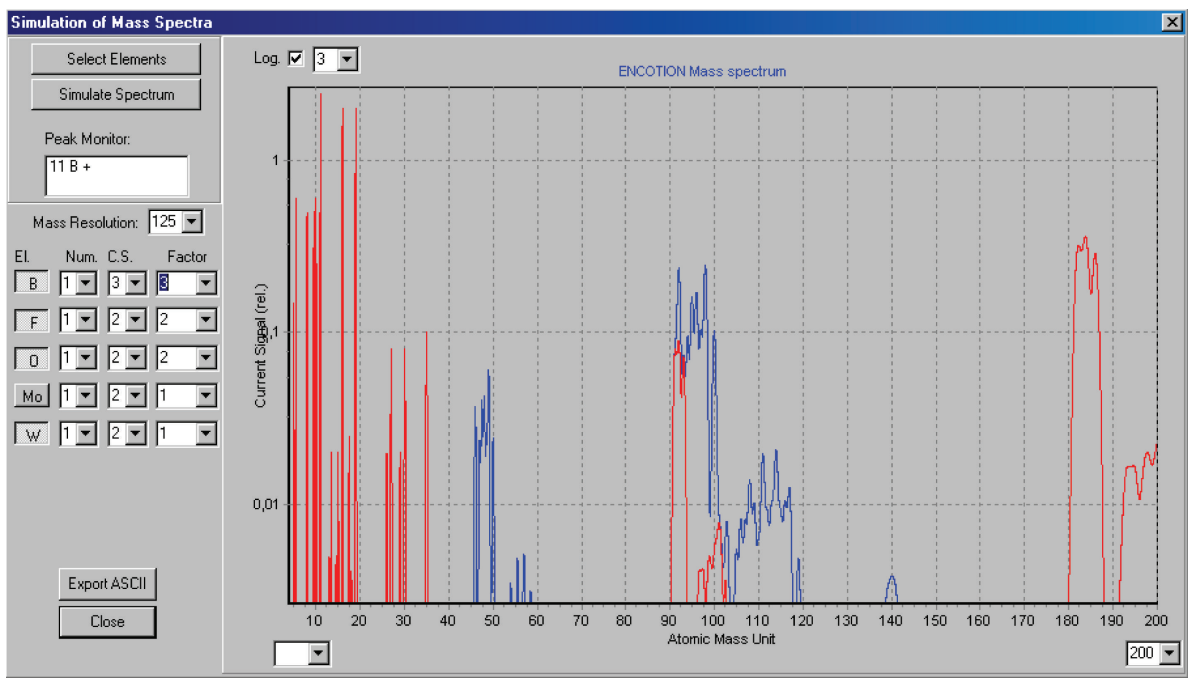

Figure 10: Mass spectrum module 2 of ENCOTION. The simulated mass spectra from 0 to $200 \mathrm{u}$ show peaks simulated by multiply charged and molecular ions of the elements B, O, F, Mo, and W. All peaks that are caused by ions containing Mo are plotted in blue.

not. In those cases, the simulations should be supported by SIMS measurements. SIMS profiles not only describe the implanted amount of considered elements, they also allow to conclude on the effective implantation energy. With the latter, the simulated transport mechanisms can be rated.

Figure 13 shows SIMS profiles of Al which were measured on two silicon wafers that were implanted with ${ }^{11} \mathrm{~B}^{+}$, one wafer with $70 \mathrm{keV}$, the other with $140 \mathrm{keV}$. The $70 \mathrm{keV}$ implant was realized with an extraction voltage of $70 \mathrm{kV}$, and the $140 \mathrm{keV}$ implant had an additional acceleration after mass separation at a voltage of $70 \mathrm{kV}$. Profile simulations with the Monte Carlo software SRIM [15] indicate that the Al was implanted at energies of $18 \mathrm{keV}$ and $74 \mathrm{keV}$, respectively. In Table 2, the two potential transport mechanisms with the lowest effective energies are listed (cp. simulations in Figure 8). The energy of the mechanism $\mathrm{Al}_{2} \mathrm{O}_{3}{ }^{+} \rightarrow$ $\mathrm{Al}_{2} \mathrm{O}_{3}{ }^{+++}$agrees very well with the energies extracted by the
TABLE 2: Simulated transport mechanisms for Al to be coimplanted during a ${ }^{11} B^{+}$-implantation. The energy $E_{1}$ results from an extraction voltage of $70 \mathrm{kV}+70 \mathrm{kV}$, and the energy $E_{2}$ from an extraction voltage and an additional acceleration voltage after mass separation of $70 \mathrm{kV}$ each (cf. Figure 8).

\begin{tabular}{lccc}
\hline Mechanism & $m_{\text {app }}(\mathrm{u})$ & $E_{1}(\mathrm{keV})$ & $E_{2}(\mathrm{keV})$ \\
\hline $\mathrm{Al}_{2} \mathrm{O}_{3}{ }^{+} \rightarrow \mathrm{Al}_{2} \mathrm{O}_{3}{ }^{+++}$ & 11.329 & 18.5 & 74.1 \\
$\mathrm{AlF}_{2}{ }^{+} \rightarrow \mathrm{Al}^{+}$ & 11.204 & 29.1 & 99.1 \\
\hline
\end{tabular}

SRIM profiles. Since alumina ceramics are present in the ion source, this mechanism appears feasible. The tails of the SIMS profiles, however, suggest that also other mechanisms such as the dissociation process $\mathrm{AlF}_{2}{ }^{+} \rightarrow \mathrm{Al}^{+}$might contribute to the contamination. 


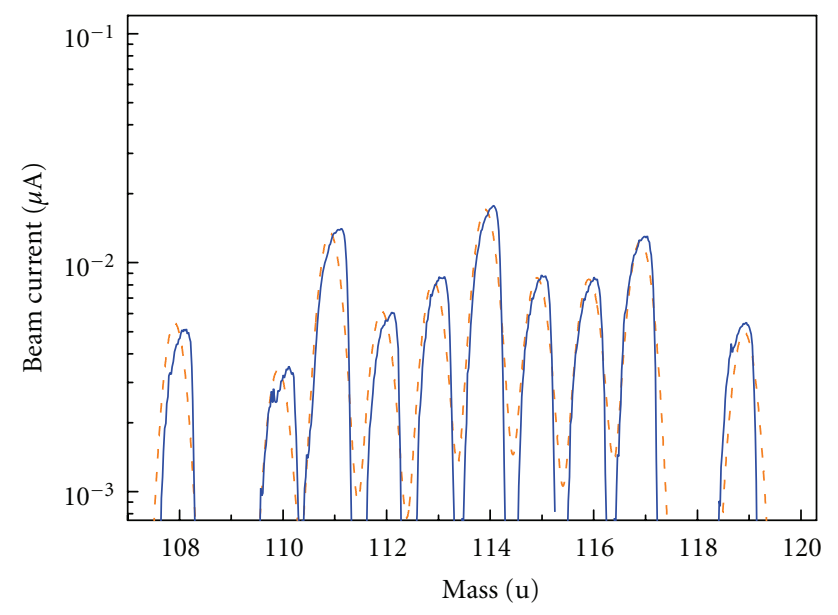

Source gas: $\mathrm{BF}_{3}$

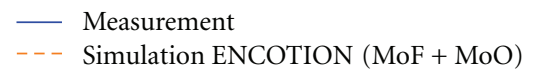

Figure 11: Peaks in a section of a $\mathrm{BF}_{3}$ mass spectrum. By simulation with ENCOTION, the peaks could be identified to result from a superposition of $58.3 \% \mathrm{MoF}^{+}$and $41.7 \% \mathrm{MoO}^{+}$ions.

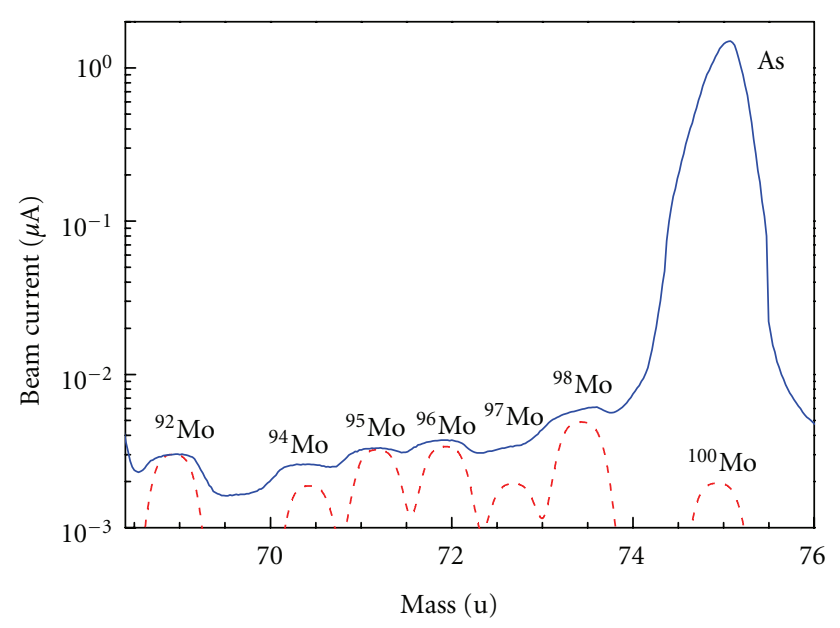

Source gas: $\mathrm{N}_{2}$ (subsequent to $\mathrm{AsH}_{3}$ )

- Measured spectrum

--- Simulation $\mathrm{Mo}^{+++} \rightarrow \mathrm{Mo}^{++}$

FIgURE 12: Comparison of a measured mass spectrum with simulated Mo signals resulting from the mechanism $\mathrm{Mo}^{+++} \rightarrow \mathrm{Mo}^{++}$. The peak of ${ }^{100}$ Mo directly overlaps with the As peak.

\section{Conclusion}

Mass spectra of an ion source being operated with $\mathrm{AsH}_{3}$, $\mathrm{PH}_{3}, \mathrm{~N}_{2}, \mathrm{BF}_{3}$, and $\mathrm{Al}$ showed a large number of charge exchange and dissociation reactions. Some of the resulting peaks depend on the ratio of the extraction to suppression voltage which can be very accurately described with the derived model of the apparent mass. This model has been implemented in the simulation tool ENCOTION which simulates, on the one side, potential transport mechanisms of

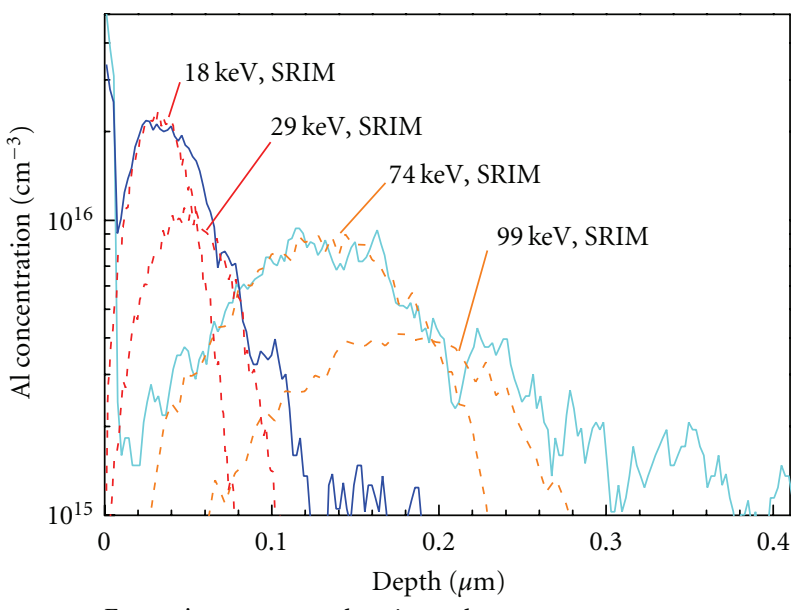

Extraction + postacceleration voltage

$70 \mathrm{kV}+0 \mathrm{kV}$

FIGURE 13: Al contamination profiles resulting from a B implantation. For comparison, with SRIM [15] simulated profiles are shown.

any ions through the magnet analyzer and, on the other side, mass spectra. The power of ENCOTION was demonstrated, firstly, by the identification of mass spectrum peaks resulting from a superposition of Mo compounds, secondly, by the detection of Mo contamination during As implantation, and thirdly, by the simulation of transport mechanism for Al during B implantation.

\section{References}

[1] H. Ryssel and I. Ruge, Ion Implantation, John Wiley \& Sons, Chichester, UK, 1986.

[2] M. J. Rendon, J. Locke, B. Brown, and D. Kamenitsa, "Reducing arsenic to germanium cross contamination with isotopically enriched SDS ${ }^{72} \mathrm{GeF}_{4}$," in Proceedings of the 13th International Conference on Ion Implantation Technology (IIT '00), pp. 707-710, September 2000.

[3] V. Häublein, L. Frey, and H. Ryssel, "The impact of mass resolution on molybdenum contamination for $\mathrm{B}, \mathrm{P}, B F_{2}$, and As implantations," in Proceedings of the 16th International Conference on Ion Implantation Technology (IIT '06), vol. 866, pp. 464-467, November 2006.

[4] A. Cubina and M. Frost, "Effects of molybdenum contamination resulting from $\mathrm{BF}_{2}$ implantation," Nuclear Instruments and Methods in Physics Research, Section B, vol. 55, no. 1-4, pp. 160-165, 1991.

[5] G. Curello, D. Carroll, J. Marley, X.-M. Zhang, N. Brooks, and $\mathrm{P}$. Mason, "Effect of $\mathrm{BF}_{2}$ induced $\mathrm{Mo}^{++}$on long retention time in $0.25 \mu \mathrm{m}$ DRAM technology," in Proceedings of the International Conference on Ion Implantation Technology Proceedings (IIT '99), J. Matsuo, G. Takaoka, and I. Yamada, Eds., pp. 550-553, IEEE, Piscataway, NJ, USA, 1999.

[6] R. B. Liebert, G. C. Angel, and M. Kase, "Tungsten contamination in $\mathrm{BF}_{2}$ implants," in Proceedings of the 11th International Conference on Ion Implantation Technology (IIT '96), pp. 135138, June 1996. 
[7] K. Funk, V. Häublein, H. Chakor et al., "Investigation of molybdenum contamination in ${ }^{11} \mathrm{~B}_{+}$and ${ }^{31} \mathrm{P}_{+}$implants," in Proceedings of the 13th International Conference on Ion Implantation Technology (IIT'00), pp. 711-714, September 2000.

[8] M. Schmeide and S. Kondratenko, "Characterization of boron contamination in fluorine implantation using boron trifluoride as a source material," in Proceedings of the 18th International Conference on Ion Implantation Technology (IIT '10), J. Matsuo, M. Kase, T. Aoki, and T. Seki, Eds., vol. 1321 of AIP Conference Proceedings, pp. 400-403, January 2011.

[9] R. C. Johnson, "Anomalous peaks in mass spectra; effects of pre-analysis dissociation and charge exchange events," in Proceedings of the 11th International Conference on Ion Implantation Technology (IIT '96), pp. 115-116, June 1996.

[10] H. Ryssel, M. I. Current, and L. Frey, "Contamination control for ion implantation," in Ion Implantation-Science and Technology, J. F. Ziegler, Ed., pp. 564-601, Ion Implantation Technology, Edgewater, NJ, USA, 2000.

[11] ENCOTION-product brochure at Fraunhofer IISB, 2011, http://www.iisb.fraunhofer.de/de/presse_publikationen/prospekte.html/.

[12] IUPAC Commission on Nomenclature of Inorganic Chemistry, "Inorganic chemistry division commission on nomenclature of inorganic chemistry," Pure and Applied Chemistry, vol. 69, no. 12, pp. 2471-2473, 1997.

[13] J. R. De Laeter, J. K. Böhlke, P. De Bièvre et al., "Atomic weights of the elements: review 2000 (IUPAC Technical Report)," Pure and Applied Chemistry, vol. 75, no. 6, pp. 683-800, 2003.

[14] V. Häublein, L. Frey, and H. Ryssel, "ENCOTION-a new contamination analysis software," in Proceedings of the 14th International Conference on Ion Implantation Technology Proceedings (IIT '03), B. Brown, T. L. Alford, M. Nastasi, and M. C. Vella, Eds., pp. 101-104, IEEE, Piscataway, NJ, USA, 2003.

[15] J. F. Ziegler, SRIM - The stopping and range of ions in matter, 2011, http://www.srim.org/. 

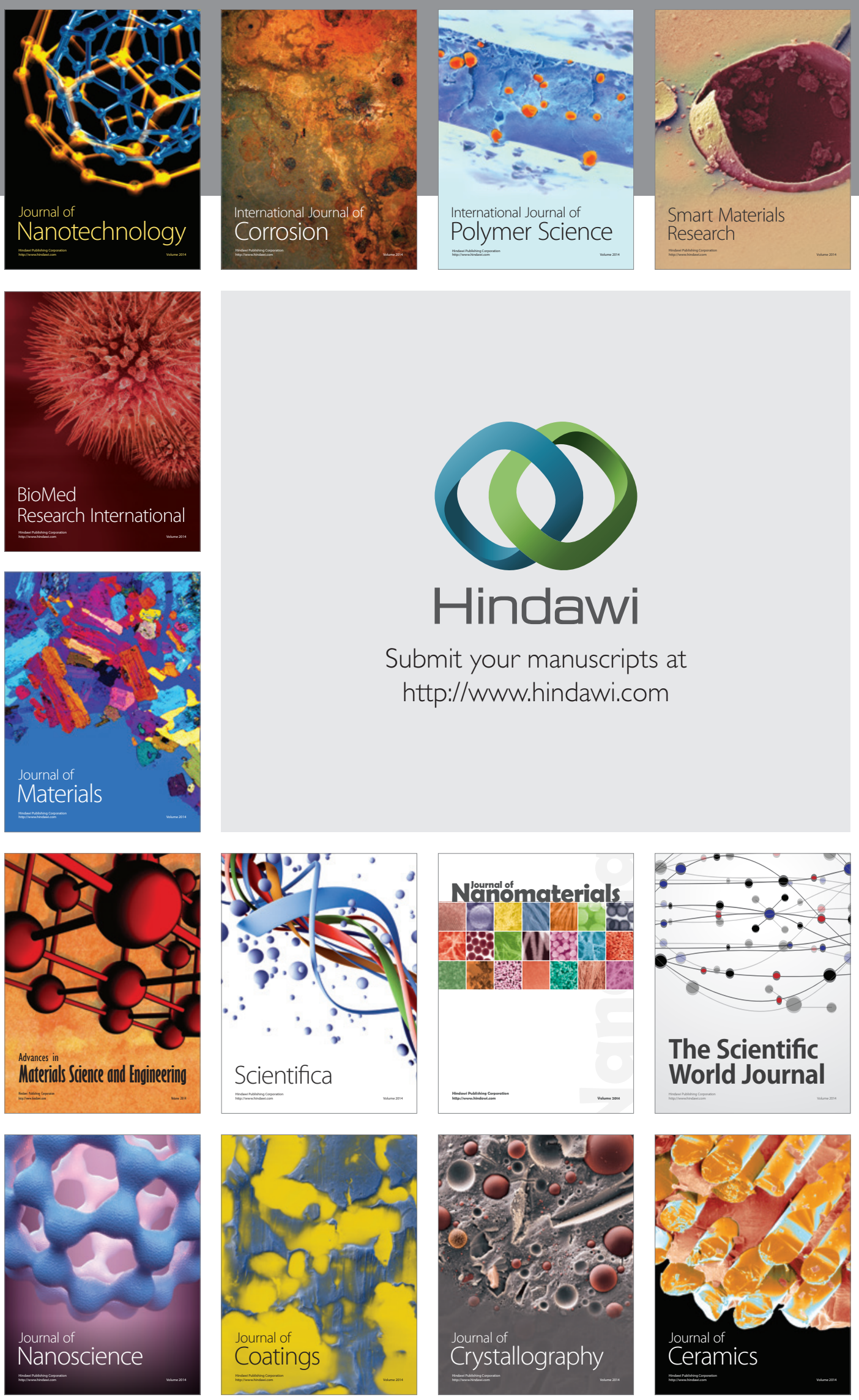

The Scientific World Journal

Submit your manuscripts at

http://www.hindawi.com

\section{World Journal}

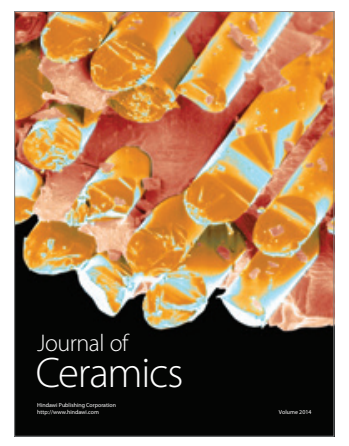

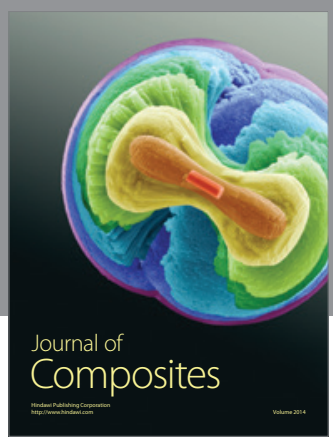
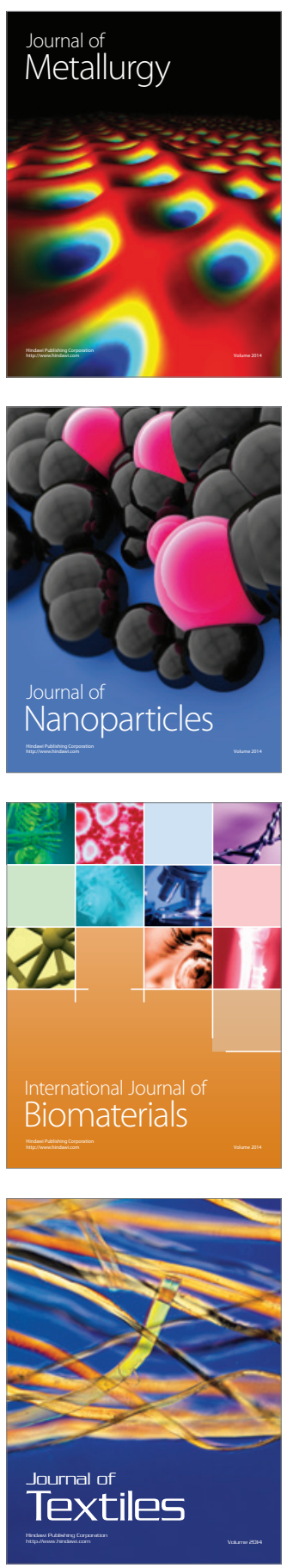